\title{
Exploring Non-Tariff Measures Facing the Indonesian Agricultural Products in FTA/CEPA Trading Partners
}

\author{
Ernawati Munadi \\ Business and Economic Faculty \\ Wijaya Kusuma University \\ Surabaya, Indonesia \\ ernamu@yahoo.com
}

\author{
Ayu Sinta Saputri \\ Center For Foreign Trade Policy \\ Ministry of Trade \\ Jakarta, Indonesia \\ ayu.sinta@kemendag.go.id
}

\begin{abstract}
Agriculture is an important sector for Indonesian economy with $21.8 \%$ contribution to non-oil and gas export, but it is observed that Indonesian agricultural products face challenges in complying with stringent non-tariff measures (NTMs) imposed by importing countries, mainly on SPS and TBT. This article tries to address some NTMs issues on Indonesian agricultural export products particularly the prevalence of NTMs using frequency ratio (FR), coverage ratio $(C R)$ and regulatory distances (RD) analysis. This study utilizes data from World Intergrated Trade Solution (WITS). The study shows that Indonesia's ability to get better market access to its major trading partners depend on its ability to comply with SPS and TBT measures, and this is reflected in their high prevalent index. However, the average coverage ratio on Indonesian agricultural exports is only $13 \%$, implying that NTMs policy on agriculture products imposed by Indonesian FTA/CEPA trading partners impacted only $13 \%$ of Indonesian agriculture export products. The RD of agricultural products between Indonesia and some of its main FTA/CEPA partners is 0.011with Pakistan and Singapore, and 0.09 with the Philippines and Australia. The finding reveals that there is a "core" of countries with similar NTM patterns at the product level on animal and food regulations.,. Indonesia is encouraged to address NTMs issues with its FTA/CEPA trading partners, in particular on any stringent NTMs and procedural obstacles related to SPS and TBT implementation as they often burden exporters.
\end{abstract}

Keywords- Frequency Index, Coverage ratio, Regulatory Distance, SPS, TBT

\section{INTRODUCTION}

Agricultural products are important for Indonesia. It contributes $21.8 \%$ to Indonesia's non-oil and gas exports with an average value of 31,469.4 Million USD in a period of 2012-2017 and grows at $1.88 \%$ annually. $55 \%$ of this figure/value is dominated by palm oil and its derivative products. In a period of $2012-2017,47 \%$ of Indonesian agriculture products wereexported to a few countries; they are India, the People's Republic of China, the United States, Malaysia and the Netherlands, and the remaining 53\% was toother destination countries. Similar for other primary products, it is observed that Indonesia's export of agricultural products faces challenges in complying with non-tariff measures (NTMs) imposed by importing countries mostly related to Sanitary and Phytosanitary (SPS) and Technical Barrier to Trade (TBT) measures. The Organization for Economic Co-operation and Development (OECD, 2018) even concluded that agricultural products face more barriers to NTMs than manufactured products from high-income to low-income countries. Using the ad-valorem equivalent indicators when exporting, NTMs impact on agricultural products is four times higher than tariff impact in low income countries i.e. $22 \%$ and $5 \%$, respectively. Similarly, the impact of NTMs on manufacturing products is double than the impact of tariff, $6 \%$ and $3 \%$ respectively. This finding is the same for both the middle-income and high-income countries that the impact of NTMs is higher than tariff's, and NTMs impact on agricultural products is higher than on manufacturing products. UNCTAD database (2019) revealed an increasing use of NTMs in contrast with the decreasing use of tariff to protect domestic industries. In APEC countries for example, the use of NTMs has increased more than $400 \%$ from only 3.165 NTMs to 16.238 NTMs between 2000-2015, growing at $10.8 \%$ annually. Research findings on NTMs in ASEAN have the same pattern and in line with this figure (Ing, et al (2016)).

This research shall address the following questions: What are the most prevalent NTMs imposed on Indonesian agricultural export by its main CEPA/FTA partners? What are the NTM coverage ratio? What are the regulatory distances between Indonesia and its main CEPA/FTA partners? The research focuses on Indonesian main FTA/CEPA partners at which Indonesian export experienced decreasing and the export share to the country is relatively low. By combining these criteria, 11 countries have been selected namely Viet Nam, USA, Thailand, Singapore, Philippines, Pakistan, Malaysia, South Korea, EU-28, Australia, and Japan. Arguably, NTMs policy imposed by Indonesian FTA/CEPA partners to protect their domestic industry has inhibited trade between Indonesia and its FTA/CEPA partners.

\section{RESEARCH METHODOLOGY}

This study utilized descriptive analysis by calculating several indices related to NTMs to understand challenges faced by Indonesian exporters of agricultural products. The NTMs prevalence is indicated by the two common indicators namely Frequency Index (FI) and Coverage Ratio (CR). This study utilized regulatory distance index (RD) to describe the different NTMs policies applied in Indonesia and its main FTA/CEPA partner countries for agricultural products. Following is details of the methods used in this study. 


\section{A. Frequency Index (FI) and Coverage Ration (CR)}

The simplest way to summarize the prevalence of NTM on trade is by calculating the incidence indicator (Deardorff and Stern, 1998). The indicator is based on policy instruments intensity. It measures the level of regulation without taking into account its impact on trade or economy. The two most commonly used indicators are FI and CR. These indicators are based on the observed NTM inventory list. FI shows the percentage of products affected by at least one NTM, while CR measures the percentage of trade affected by NTM policy.

$F I_{i}=\frac{\sum_{k=1}^{h s} N T M_{i k} D_{i k}}{\sum_{k=1}^{h x} D_{i k}} 100$

$C R_{\mathrm{i}}=\frac{\sum_{\mathrm{k}=1}^{h S} N T M_{\mathrm{ik}} X_{\mathrm{ik}}}{\sum_{k=1}^{h x} X_{\mathrm{ik}}} 100$

where $\mathrm{k}$ denotes the product and $\mathrm{i}$ country that applies the NTM policy. NTM $_{i k}$ is a dummy variable shows the existence of NTM (or NTM types) at the aggregation level of the selected hs (HS6 or HS4), X is import value, and D are dichotomous variables that take value 1 when country $\mathrm{i}$ imports a number of products $\mathrm{k}$, and zero otherwise. Some studies which utilized the frequency index and coverage ratio, among others are Hertanti (2017), Melo and Nicita (2018), and Cadot et all (2018).

\section{B. Regulatory Distance (RD)}

$\mathrm{RD}$ indicates the percentage at which the combinations of product-NTMs in two countries are not the same. Smaller index shows better similarity of regulatory framework between two countries. Similar to other incidence indicators, $\mathrm{RD}$ can be calculated at the sector level and for certain types or groups of NTM. The RD can be calculated using the following equation.

$$
R D_{\mathrm{ij}}=\frac{1}{N} \Sigma_{k} \Sigma_{z}\left|N T M_{\mathrm{ik}}^{Z}-N T M_{j k}^{Z}\right|
$$

where NTM is a dichotomous variable that takes a value of 1 when country applies z-type NTMs, and zero if it does not apply. $\mathrm{z}$ shows the type of NTM, $\mathrm{k}$ shows product $\mathrm{j}$ and $\mathrm{i}$ shows country $\mathrm{i}$ and $\mathrm{j}$.

By calculating the RD indicator, countries that have different types of NTMs than Indonesia, will be identified. The smaller the RD index the greater the similarity of the types of NTMs used by Indonesia and FTA/CEPA partner countries. Conversely, the greater RD indicator the greater the difference between NTMs used by Indonesia and its main partner countries of CEPA/TFA.

\section{Data and Analysis}

The selected indicators will be calculated to understand the NTMs on Indonesian Agricultural Products applied by its FTA/CEPA Trading Partners. The definition of agricultural products is according to UNCTAD that refers to the Harmonized System (HS) of product classification within Chapters 1 to 24. The agricultural products are grouped into 4, namely animal (01-05), vegetable (06-14), animal vegetables and oils (15) and food products (16-24).

\section{RESULTS AND DISCUSSIONS}

This part discusses results of analysis. To simplify the discussion, the session will be discussed according to the research objective.

\section{A. Frequency Index (FI) and Coverage Ratio (CR)}

This part will summarize the frequency index to understand the incidence of NTMs and the coverage ratio to understand the impact. Figure 1 illustrates the incidence of NTMs in 11 countries and their impact to trade on all products. Those countries are the main Indonesian CEPA/FTA partners, with the European Union (EU) treated as one country. The results show the averaged FI is $75.5 \%$ implying that $75.5 \%$ of Indonesian export tariff lines to its main CEPA/FTA partners are subject to at least one NTMs or more. Those NTMs policy that impacted $75.1 \%$ of Indonesian export are shown by its coverage ratio at Figure 1. This also shows that USA, Thailand, Pakistan and Malaysia use lesser NTMs than other countries.

The USA has the lowest FI than other Indonesian CEPA/FTA partners. The USA's FI for all products is $42.1 \%$, implying that $42.1 \%$ out of total USA's import tariff lines on products exported by Indonesia are subject to at least one NTM (Figure 1a), affecting about $46 \%$ of imports, as indicated by a coverage ratio of 0.46 .

The Indonesia's CEPA/FTA partners with the highest FI for all products are Singapore, Australia, and Viet Nam reaching almost $100 \%$ means that all tariff lines for products exported by Indonesia to those countries are affected by at least one NTM. Those NTM policy affect almost $100 \%$ of Indonesian exports to Australia and Viet Nam as indicated by $100 \%$ of the CR index, and $97 \%$ to Singapore.

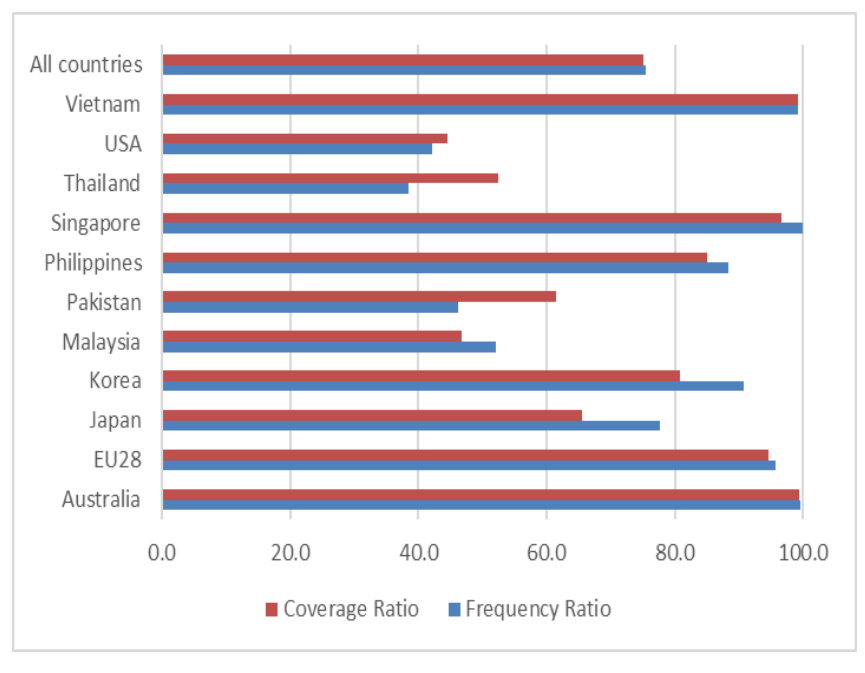

Source: World Integrated Trade Solution database, analysed

Fig. 1. Frequency Index and Coverage Ration of Indonesian main CEPA/FTA, total

Figure 2 shows both frequency index and coverage ratio on agricultural products exported by Indonesia to its main CEPA/FTA Partners. The figure reveals that FI of agriculture is $17 \%$ higher than FI for all products, at $91.2 \%$ and $75.5 \%$, respectively. This implies that agricultural products are more protected than other products. This finding is not surprising as income per capita from those Indonesia CEPA/FTA increased 100\% during 2000-2018 
from US\$ 14,417 in 2000 to US\$ 28,851 in 2018 . Hummels and Lugovskyy (2009) in Ing et al. (2016) observed that when the income level of a country rises, indeed the average unit value of a country's imports tends to increase. Higher income made consumers switch to higher-quality and safer products, with or without standards. The NTMs policy implemented in Indonesia's CEPA/FTA partners only impacted $16 \%$ of Indonesian exports of agriculture.

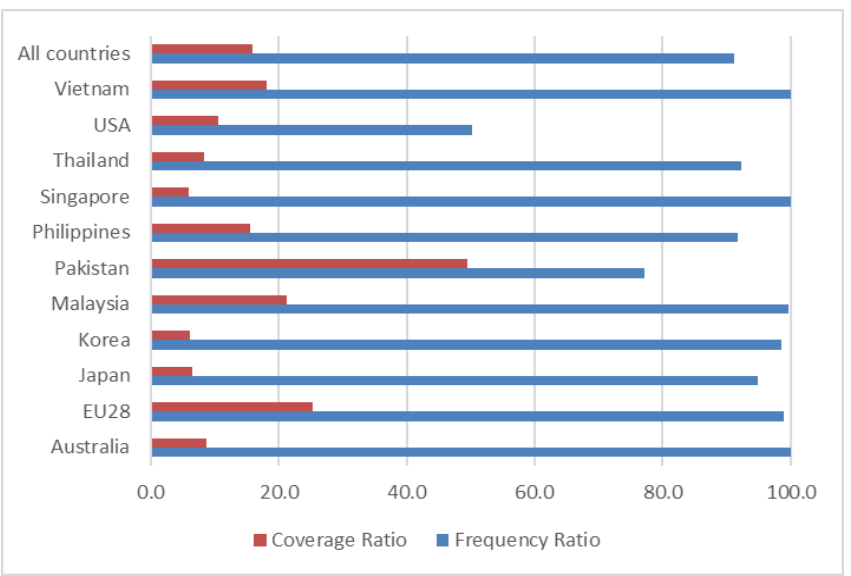

Source: World Integrated Trade Solution database, analysed

Fig. 2. Frequency Index and Coverage Ratio of Indonesian main CEPA/FTA, Agriculture Products

Figure 3 and 4 show the disaggregated-frequency index and coverage ratio of NTMs by agricultural products facing by Indonesian exports to its CEPA/FTA partners. It is broken down into 4 agriculture products groups namely, animal, vegetables, animal or vegetables oils, dan food products.

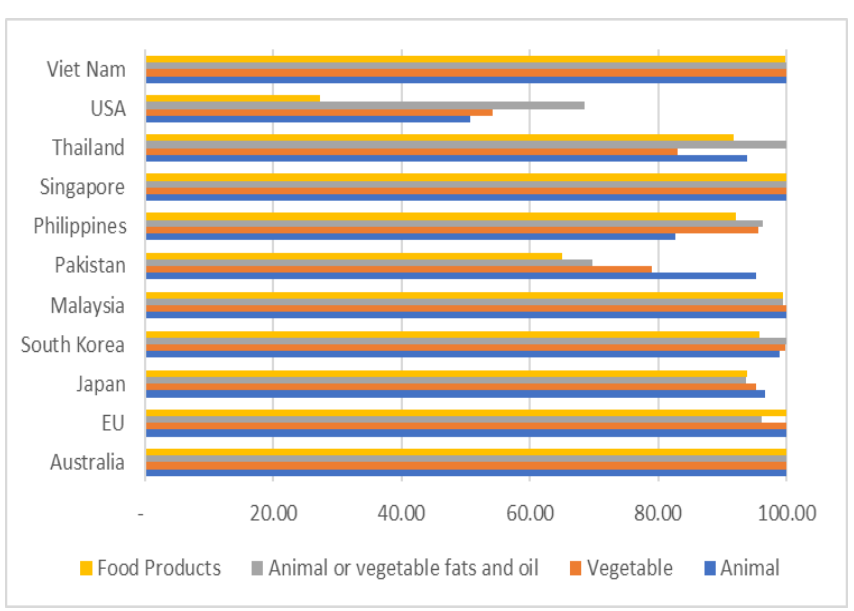

Source: World Integrated Trade Solution database, analysed

Fig. 3. Frequency Index of Indonesian main CEPA/FTA Partner, Agricultural products

Figure 3 tells the USA FI for agriculture products is 0.5 , implying that $50 \%$ of USA's import tariff lines on agriculture products imported from Indonesia are subject to at least one NTM, affecting about $11 \%$ of imports, as indicated by a coverage ratio of 0.11 (Figure 4). Figure 3 with nearly to $100 \%$ FI except for USA, Thailand, Philippines, and Pakistan, means that the use of NTMs on Indonesian agricultural export products is very intensive. The FI for NTMs policy on agricultural products implemented in Viet
Nam, Singapore, Australia, Malaysia, and EU28 almost reaches $100 \%$. The NTMs policy implemented in Viet Nam has affected $18 \%$ of Indonesian exports of agricultural products, less than Malaysia that accounted for $21 \%$. The impact of NTMs policy is even lower in Singapore $(6 \%)$ and Australia (9\%) (See Figure 4).

The use of NTMs on Indonesian agricultural exports products by countries like Malaysia, EU, Pakistan and Viet Nam, has impacted the products at more than $10 \%$, while in other countries it impacted less than $10 \%$ (see Figure 4). The biggest impact was derived from Pakistan's NTMs policy that stood at almost 50\%, whilethe least one was from Singapore at 6\%. Pakistan's (and EU28) NTMs policy mostly impacted vegetables products, whereas impact from other countries was distributed to all agricultural products groups.

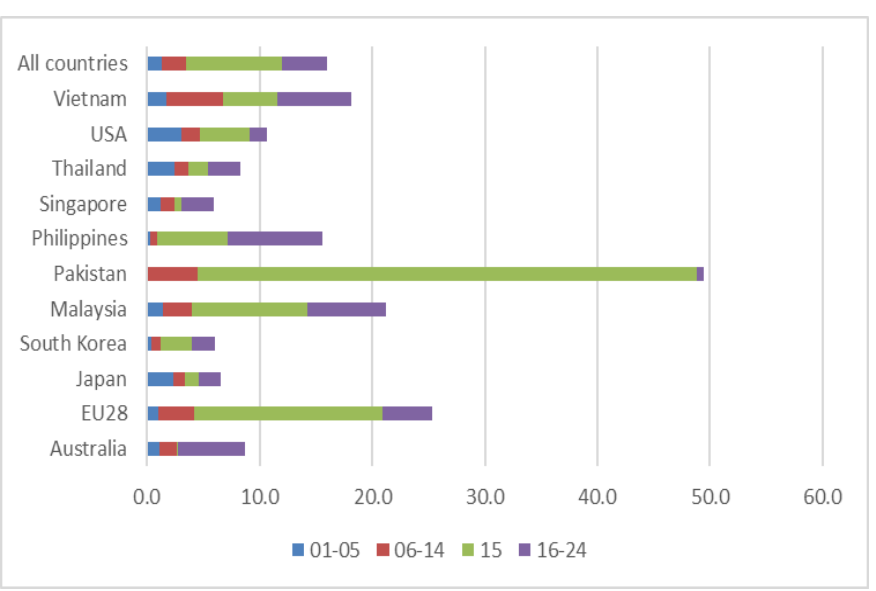

Source: World Integrated Trade Solution database, analysed

Fig. 4. Coverage Ratio of Indonesian main CEPA/FTA Partners, Agricultural products

\section{B. NTMs Faced by Indonesian Agricultural Products on the Importing countries}

Figure 5 shows the results of FR analysis on Indonesian agricultural exports products to the main FTA/CEPA partner countries based on the type of NTMs. Based on Figure 5, the most common type of NTMs encountered is the SPS measures, that cover over $60 \%$ of the total NTMs faced by Indonesian agricultural products. Other dominated NTM policies are TBT measures and price control that reach $24 \%$ and $8 \%$ of the total NTMs respectively.

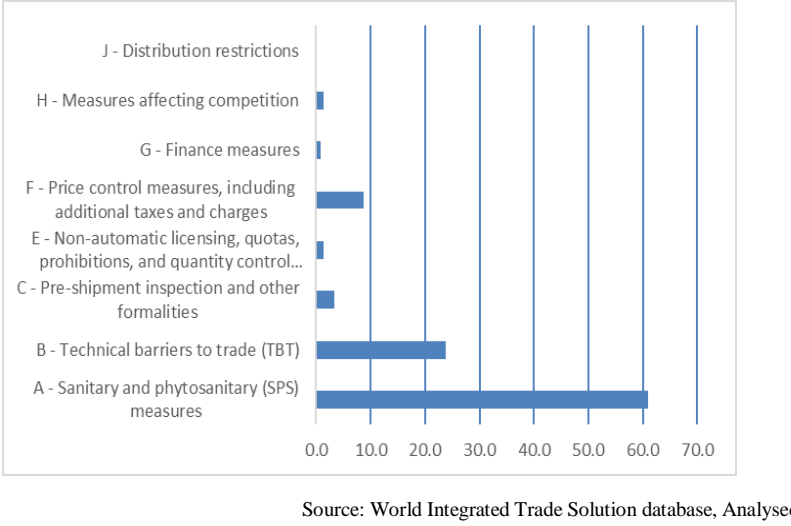

Fig. 5. Frequency Index on Agriculture products, by Type of NTMs 
SPS policies that impact Indonesian agricultural exports products the most are labeling requirements for SPS reason $(5.2 \%)$, import approval measures $(3.8 \%)$, packaging requirement $(3.5 \%)$, certification requirement $(3.4 \%)$ and restriction used of substance $(3.3 \%)$. Meanwhile, some TBT measures that have the most influence on the export of Indonesian agricultural products are labeling requirements for TBT reason $(5.2 \%)$, import approval measures $(3.5 \%)$, standard requirements $(1.2 \%)$, packaging requirement $(1.6 \%)$, and certification requirements $(1.5 \%)$.

This results reveal that Indonesian exports of agriculture products largely depends on its ability to comply with NTMs policy. This is supported by the fact that the tariff level on those countries has significantly decreased since 2000. The average tariff on the 11 Indonesian main CEPA/FTA partners declined remarkably within 2010-2018. During this periods, tariff has decreased $6.4 \%$ annually, with the average tariff at $5.4 \%$ from the previous rate at $12.9 \%$. Tariffs declined as a result of commitments implementation made under regional and multilateral cooperation.

\section{Regulatory Distance on Indonesian Agricultural Products and its main FTA/CEPA Partners}

This study shows that RD value between Indonesia and and its main FTA/CEPA partners on agricultural products ranges from 0.011 with Pakistan and Singapore to 0.09 with the Philippines and Australia. This result is consistent with other research findings. For example, Cadot (2015) concluded that the RD value is usually small number between zero and one. He found in his study that the RD value ranges from 0.009 between Madagascar and the United Republic of Tanzania to 0.304 between China and Nepal.

Figure 6-9 show the resulting projection on a twodimensional space for regulatory distance between Indonesia's agriculture product groups and its CEPA/FTA partners. In order to interpret the figure, note that the axes are arbitrary: they are scaled so as to fit the range of bilateral distances and merely represent the cardinal points in which distances are mapped. The figures suggest several observations.

First, among the agriculture products groups namely animal (01-05), vegetable (06-14), animal vegetables and oils (15) and food products (16-24) the findings reveal that there is a "core" of countries with similar NTM patterns at the product level. But it only happened on the animal and vegetable product groups, and this provides a sort of common pattern of NTM regimes (See Figure 6 and 7). For animal and vegetable products groups, it is remarkable to see how consistently close Indonesia with Viet Nam, USA, Thailand, Singapore, Pakistan, Malaysia, South Korea, Japan, and EU.

Second, Australia and Philippines do indeed stand out $\mathrm{t}$ from the group. This implies that both countries relatively have dissimilarity on agricultural regulation structure compared with the other nine countries.

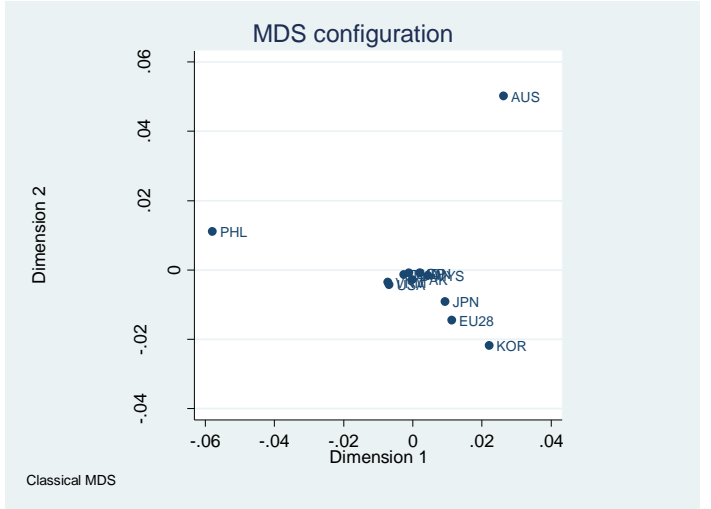

Source: World Integrated Trade Solution database, analysed

Fig. 6. The Regulatory Distance of Indonesian and Its main FTA/CEPA Trading Partners on Animal Regulation

Third, for animal or vegetable fats and oil products (Figure 8) and food products (Figure 9), the regulation dissimilarity is bigger and stands out for unusual patterns of NTM imposition. However, as the main palm oil producer Indonesian animal or vegetable fats and oil regulation is relatively very close to Malaysia, which isthe world's second largest palm oil producer.

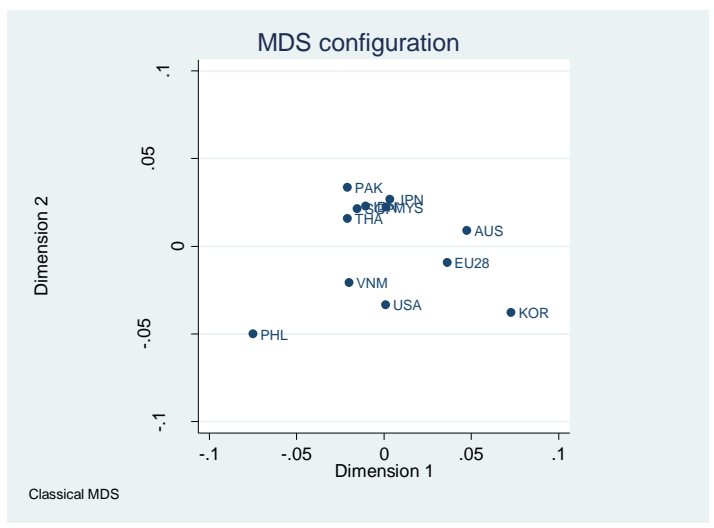

Source: World Integrated Trade Solution database, analysed

Fig. 7. The Regulatory Distance of Indonesia and its FTA/CEPA Trading Partners on Vegetable Regulation

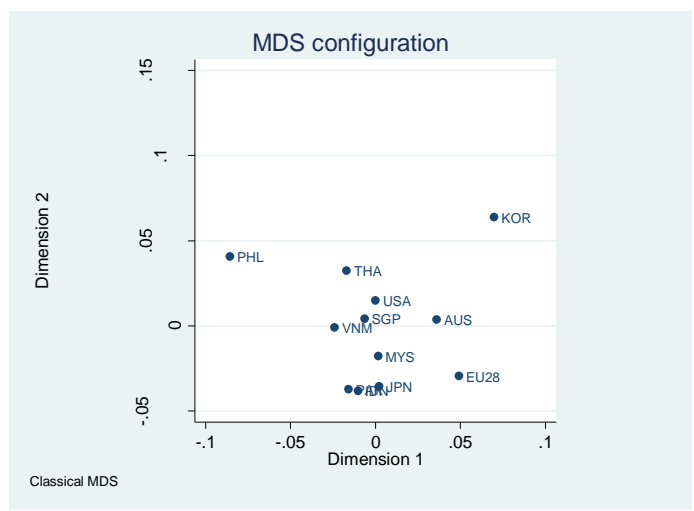

Source: World Integrated Trade Solution database, analysed

Fig. 8. The Regulatory Distance of Indonesia and its FTA/CEPA Trading Partners on animal or vegetable fats and oil Regulation 


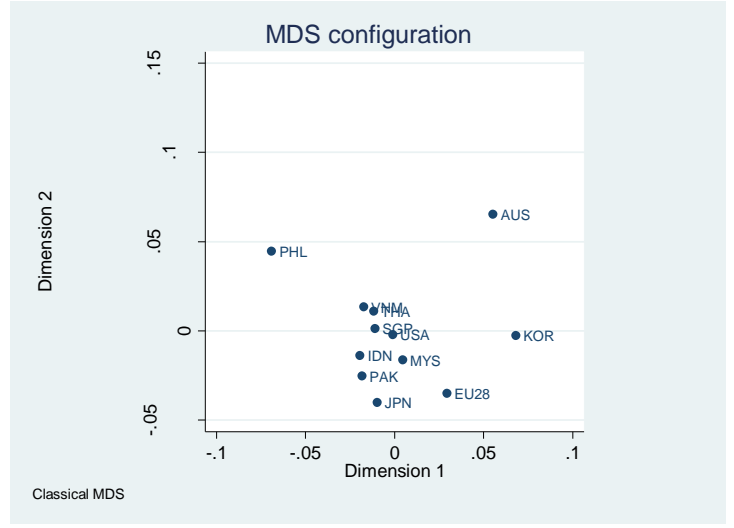

Source: World Integrated Trade Solution database, analysed

Fig. 9. The Regulatory Distance of Indonesia and its FTA/CEPA Trading Partners on Food Products regulation

Philippines's position as an outlier is particularly striking, suggesting that the process of regulatory harmonization envisaged by ASEAN framework is relatively far from completion even at the relatively crude level of the regulatory structure. Australia's position as well as an outlier in the analysis results indicates that regulatory structure in Australia is quite different from the regulatory structure in Indonesia. On the one side, Indonesia can learn from Australia on how to make legitimate policies that hamper the market access of Indonesian's exports.

\section{SUMMARY AND CONCLUSIONS}

Some important conclusions from this study are first, technical measures, especially SPS and TBT, are the dominant types of NTMs and the main obstacles to the export of Indonesian agricultural products in some of the main partner countries of CEPA / FTA. This means that Indonesia's ability to improve market access in these countries is largely determined by Indonesia's ability to meet the requirements of SPS and TBT.

Second, except for USA, Thailand and Pakistan, the use of NTMs against agricultural products exported by Indonesia is very intensive, as shown by FI which is almost $100 \%$. The averaged agriculture FI is $17 \%$ higher than all products. However, those NTMs are only impacted $13 \%$ of total Indonesia export of agriculture products.

Third, the results of RD's analysis show that Indonesia's regulatory structure on agricultural products is in common with NTMs policies implemented by its several key CEPA/FTA partner countries . Result from two out of four agricultural products groups tested shows that policies in the Philippines and Australia tend to be relatively different from other countries. For this reason, Indonesia needs to seriously raise the NTMs issues when holding negotiations with Australia, especially on any stringent NTMs and procedural obstacles as they burden exporters related to SPS and TBT implementation. It is believed that reducing the distance of the regulatory distance could accelerate a deeper cooperation between countries.

\section{ACKNOWLEDGMENT}

The author is grateful to the Ministry of Trade. Special thanks to Research Department (BP3) at the Ministry of Trade of having this International Conference as through this international seminar author has been encouraged to produce this publication. Special thanks is also given to Scientific committee for their comments during the writing process.

\section{REFERENCES}

[1] Deardorff, Alan V. and Stern, Robert M., Measurement of Nontariff Barriers (1997). A1.159 WP 395. Available at SSRN: https://ssrn.com/abstract=54045 http://dx.doi.org/10.2139/ssrn.54045

[2] Ing, L.Y., S.F. Cordoba, and O. Cadot, "Non-Tariff Measures in $A S E A N$ ". Book chapter. Jakarta: Economic Research Institute for ASEAN and East Asia and United Nations Conference on Trade and Development, 2016.

[3] World Integrated Trade Solution, http://wits.worldbank.org/WITS/WITS/Default-A.aspx?Page=Default (accessed 17 February 2019).

[4] Cadot, O., M.J. Ferrantino, J. Gourdon, and J.D. Reyes, "Reforming Non-Tariff Measures: From Evidence to Policy Advice". Washington, DC: The World Bank Group, 2018.

[5] Hertanti, R. (2017), 'Indonesian Trade and Investment Policy in the Trend of Global Protectionism', paper presented at The Eurodad Conference, Den Hague, The Netherlands, 21 June

[6] Melo, J. and A. Nicita (2018), 'Non-tariff measures: data and analytical tools', in Non-Tariff Measures: Economic Assessment and Policy Options for Development. Paris: United Nations Conference on Trade and Development

[7] Cadot., O., Asprilla, A., Gourdon, J., Knebel, C., and Peters, R. "Deep Regional Integration and Non-Tariff Measures: A Methodology For Data Analysis", Policy Issues In International Trade And Commodities, Research Study Series No. 69, The United Nations Conference on Trade and Development (UNCTAD), 2015.

[8] The Organisation for Economic Co-operation and Development (OECD).

[9] The United Nations Conference on Trade and Development (UNCTAD). Non-Tariff Measures Database, https://trains.unctad.org/ (accessed January 2019). 